ISSN: 2174-5609

DOI. http://dx.doi.org/10.14198/INTURI2016.12.04

TJT Investigaciones

$\Delta$ TURISTICAS

\title{
El enoturismo de Baja California, México: un análisis de su oferta y comparación con la región vitivinícola de La Rioja, España
}

\author{
Lino Meraz Ruiz \\ Centro de Enseñanza Técnica y Superior (CETYS), México \\ lino.meraz@uabc.edu.mx \\ Agustín V. Ruiz Vega \\ Universidad de La Rioja, España \\ agustin.ruiz@unirioja.es
}

\section{RESUMEN}

Este trabajo presenta los resultados de un estudio posdoctoral durante el primer año, cuyo objetivo fue analizar el modelo de enoturismo y desarrollo territorial de La Rioja, en España, para su comparación con el Estado de Baja California, México, de tal forma que se permita conocer el potencial real de crecimiento mediante el comportamiento de oferta del enoturismo. La metodología estuvo compuesta en una primera etapa en donde se desarrolló e identificó el modelo de enoturismo de las zonas vitivinícolas de Baja California, se caracterizó una muestra representativa de 64 bodegas del Valle de Guadalupe, y se registró una base datos completa de empresas que ofertan enoturismo en los valles del vino de Baja California. Los primeros resultados indican que el modelo de enoturismo se conjuga en la oferta de productos y servicios de promotores, restauradores, hoteleros o alojamientos turísticos, y bodegas de cuatro rutas del vino, conformada por 20 promotores, 50 restaurantes, 27 hoteles y 95 bodegas. Siendo la muestra conformada por el $59.4 \%$ de tamaño micro, $18.8 \%$ pequeñas y $10.9 \%$ medianas. Cumpliéndose satisfactoriamente con el objetivo de la primera etapa de la investigación.

Palabras clave: Baja California, La Rioja, enoturismo, vino. 


\title{
Wine tourism in Baja California, Mexico: An analysis of its supply and a comparison with the wine region of La Rioja, Spain.
}

\begin{abstract}
This paper presents the first-year results of a postdoctoral study, which analyses the model of wine tourism and territorial development of La Rioja, Spain, so that it may be compared with Baja California, Mexico. By observing the behavior of the different wine tourism options, the real growth potential of the region can be determined. The methodology comprises a first stage in which the model of wine tourism of the wine regions of Baja California is developed and identified. A representative sample of 64 wineries in Valle de Guadalupe was constructed and a database of all of the companies offering wine tourism in the wine valleys of Baja California was created. The preliminary results reveal that the wine tourism model is built into the products and services offered by developers, restauranteurs, hotel or tourist accommodation, and wineries of four wine routes, consisting in 20 promoters, 50 restaurants, 27 hotels and 95 wineries. Micro-sized companies represent $59.4 \%$ of the sample, small companies constitute $18.8 \%$ and medium-sized companies make up $10.9 \%$. The findings satisfactorily fulfil the objective of the first stage of the research project.
\end{abstract}

Keywords: Baja California, La Rioja, wine tourism, wine.

\section{INTRODUCCIÓN}

En la búsqueda de entretenimiento, diversión, desarrollo de nuevas formas de ocio, hábitos y costumbres, el hombre ha recurrido a distintas actividades que emanan de la oferta turística de una localidad o región (Pérez et al., 2015a). Este tema como eje central de estudio ha sido analizado desde distintas vertientes, como la económica-social, y de su oferta y demanda (Palmas et al., 2014). Es por ello que el turismo además de ser un sector muy dinámico que está adaptándose a los gustos y demandas de los viajeros, en la búsqueda de experiencias (Vieira et al., 2013), también se le ha venido considerando como un recurso de gran potencial para destinos turísticos maduros y específicos (Prat y Cànoves, 2014), sobre todo áreas rurales geográficas (Pérez et al., 2015b).

En la apuesta por la dinámica turística, según información de la Organización Mundial de Turismo, México recibió la llegada de 29.1 millones de turistas internacionales durante el 2014, representando un aumento del $20 \%$ al año anterior, lo que le ha permitido subir cinco posiciones y establecerse dentro del Top Ten del Barómetro del Turismo Mundial. Esto significa que uno de cada 39 turistas internacionales que viajaron se dirigió al territorio mexicano. Siendo el primer destino de turistas internacionales en América Latina y el segundo destino de América del Norte (Mexican Business Web, 2015).

En términos de competitividad, el país ocupa el lugar 30 de 141 países, posicionándose como el segundo más competitivo después de Brasil y el número 18 en cuanto a búsquedas online por los turistas (Centro de Documentación Turística, 2015). Entre las principales fortalezas de México se encuentran sus recursos naturales y culturales, pero, en cambio, se debe trabajar en aspectos de seguridad y sustentabilidad (Paredes, 2015). A pesar de ello, las tasas de crecimiento irán en aumento (Organización Mundial del Turismo, 
2015) y, según la World Travel \& Tourism Council, esta actividad se expandirá en un $6.1 \%$ en el 2015 (Amador, 2015).

Por su parte, el Gobierno de la República a través del Plan Nacional de Desarrollo (PND) 2013-2018, indica que durante el 2014 se tuvo una captación de 16.258 millones de dólares como producto del arribo de turistas por vía aérea y marítima, lo que representó un aumento de $16.6 \%$ respecto a 2013. Atendiendo a lo anterior, el PND con apoyo del Programa Sectorial de Turismo 2013-2018 y el Programa Nacional de Infraestructura 20142018, establece como medidas prioritarias: modernizar los puntos de entrada para el turismo internacional, impulsar la innovación de la oferta y competitividad del sector turístico, fortalecer la infraestructura y calidad de los servicios turísticos, fomentar la investigación y generación del conocimiento turístico (turismo de naturaleza o alternativo), incentivar las inversiones turísticas de las micro, pequeñas y medianas empresas (MIPYMES), entre otras. También, en dicho Plan, se tiene registro que al país ingresaron 16.258 millones de dólares con motivo de esta actividad (Segundo Informe de Ejecución, 2014: 450).

Dentro de esta óptica y en atención a la diversificación del turismo, principalmente al arribo de cruceros, se ha podido aprovechar el potencial natural y cultural existente para conformar un producto turístico único, como atracción de nuevos segmentos de mercado que se están consolidando en el territorio, tal es el caso del turismo rural, ecoturismo y enoturismo, que figuran como una triada del turismo alternativo (Bringas e Israel, 2004). Especialmente este último denominado enoturismo, desempeña un papel importante como una vía complementaria a nivel nacional para la generación de empleo y riqueza, y como ente diversificador de la oferta turística, de forma particular para las zonas rurales (Alpizar y Maldonado, 2009).

Conforme a la Carta Europea del Enoturismo de la Unión Europea, los autores Ruiz y Pelegrín (2011) definen al enoturismo como todas aquellas actividades de ocio y tiempo libre que están relacionadas con el patrimonio cultural, el vino y la gastronomía autóctona de la región, y que se resume en la experiencia de visitar viñedos, bodegas, asistir a festivales y demostraciones vinícolas acompañados del disfrute de una cata de vino, siendo el principal motivo de su visita (Hall y Mitchell, 2000).

Por su parte, la Secretaría de Turismo anunció algunas líneas de acción y políticas públicas encaminadas al apoyo de los productores de vino del norte de México, a fin de consolidar los principales retos y áreas de oportunidad de la industria vitivinícola, la que actualmente se integra por más de 200 bodegas y productores independientes de uva para vino, de ellos el $97 \%$ se ubican en las principales zonas vitivinícolas del país, como: Baja California (zona más reconocida por la elaboración de vinos), Coahuila, Querétaro, Zacatecas, Guanajuato y Aguascalientes (Celaya, 2014; Grupo Fórmula, 2015).

Como respuesta a lo anterior, existen pocos estudios que examinan el tema del enoturismo o de las zonas vitivinícolas en México, siendo en su mayoría descriptivos, comparativos o con enfoques meramente económicos, dejando de lado el aspecto turístico, es decir, en cuanto a la oferta de productos y servicios de las empresas. Entre los que se encuentran: Alpizar y Maldonado (2009); Bringas e Israel (2004); Quiñónez et al. (2012); Ruiz (2014); Ruiz et al. (2011); y Velásquez (2007). Cabe destacar que la mayor parte de estos han sido tratados en la zona vitivinícola de Baja California y, en segundo término, en el estado de Querétaro. 
La investigación que aquí se presenta fue realizada en el marco del proyecto de investigación COO/1091/14 de Estancias Posdoctorales al Extranjero para la Consolidación de Grupos de Investigación (El modelo de enoturismo y desarrollo territorial de La Rioja, España, con aplicación a la industria vitivinícola de Baja California, México), aplicado al Área del Conocimiento: Ciencias Sociales, Económicas y Políticas, financiado por el Consejo Nacional de Ciencia y Tecnología (CONACYT).

Por ende, resulta interesante que este estudio haya sido concebido con el objetivo de analizar el modelo de enoturismo en cuanto a la oferta por parte de las empresas vinícolas de dos regiones: Baja California y La Rioja; de tal forma que permita establecer comparaciones y una metodología para obtener información enoturística de Baja California a través de la consolidación de una base de datos completa de empresas que ofrecen dicho servicio. También, se establece como objetivos secundarios conocer cómo son estas empresas y quiénes son los verdaderos oferentes del enoturismo y sus elementos de valor en ambos territorios.

Así, el presente artículo ha sido dividido en las secciones que se enumeran a continuación: la Sección II, aborda una revisión teórica del tema del enoturismo en México, específicamente en Baja California. En la Sección III, se plantean los aspectos metodológicos y descriptivos del ámbito en que se enmarca el estudio. En la Sección IV, se discuten los resultados encontrados para el desarrollo del modelo de enoturismo y la caracterización de una muestra realizada. Finalmente, en la Sección $V$, se presentan las principales conclusiones y se proponen futuras investigaciones.

\section{CONTEXTO ENOTURÍSTICO EN MÉXICO}

Siguiendo a Ruiz et al. (2011) el enoturismo en México se encuentra en una fase inicial, enmarcado por el reconocimiento nacional e internacional de la calidad de los vinos y el gusto de experiencias enológicas únicas, como complemento de los productos tradicionales de sol y playa y cruceros que satisfacen la actividad turística y potencia el desarrollo económico del territorio (Quiñónez et al., 2012).

En su aspecto contextual, en México se destinan alrededor de 3500 hectáreas para el cultivo de la vid, de ellas 2500 se ubican en los valles bajacalifornianos, distribuidas en el estado de Baja California con $83 \%$, seguido de Querétaro con $8 \%$, Coahuila $4 \%$ y Zacatecas $3 \%$, lo que se traduce en 14 millones de litros al año, una facturación de 40 millones de dólares y siete mil empleos directos e indirectos (Ruiz, 2014).

La capacidad productiva de vino nacional no lo ubica entre los diez mayoritarios a nivel internacional (López y Sotelo, 2014), dado que en comparación con los países que compite aporta solamente $0.38 \%$ de la producción mundial, lo que le lleva al lugar número 24. Ubicándolo muy por debajo de países como España, Francia, Italia, Estados Unidos, Argentina, Alemania y Chile (Ruiz, 2014). Este nivel productivo es un factor que sugiere mayor atención, puesto que continúa siendo inferior a la cantidad importada, y es que $65 \%$ del vino que se consume es de procedencia extranjera (Instituto Español de Comercio Exterior, 2012).

Precisamente, en términos de consumo es de los más bajos del mundo, siendo de $600 \mathrm{ml}$. per cápita al año, a diferencia de los 28 litros que se consume en otros países como España, Italia o Francia (López y Sotelo, 2014; Ruiz, 2014). No obstante, México está reconocido como un mercado emergente y susceptible a triplicar el consumo de vino en los 
siguientes seis años (Celaya, 2014). En respuesta a ello, las vinícolas han comenzado a dirigir sus productos hacia un mercado joven de 20 y 30 años a través del canal HORECA ${ }^{1}$, exclusivamente $62 \%$ en restaurantes situados en Ciudad de México, Monterrey, Guadalajara y zonas costeras turísticas como Ensenada, Cancún y Los Cabos, en Baja California Sur (Instituto Español de Comercio Exterior, 2012).

Las importaciones se han elevado considerablemente en los últimos años como consecuencia de los tratados comerciales con países de Latinoamérica y Europa, en los que se encuentran Chile (Valle del Maipo), tras el Tratado de Libre Comercio de América del Norte en 1999, y España (DO ${ }^{2}$ Rioja y Ribera del Duero) y Francia, con el Tratado de Libre Comercio entre México y la Unión Europea en 2000 , de donde proviene $72 \%$ del vino importado. Aunado a ello, los vinos provenientes de Argentina, Italia y Estados Unidos (Napa Valley) suman aproximadamente $90 \%$ del vino extranjero (Freitas, 2015; Ruiz, 2014; Instituto Español de Comercio Exterior, 2012).

La mayor parte de las ventas de vino en el territorio mexicano se realizan en restaurantes, hoteles y tiendas especializadas, aunque la tendencia está volcándose hacia la venta vía comercio electrónico on-line a través de páginas Web en Internet. Muy pocas bodegas exportan su producto (López y Sotelo, 2014), pero debe reconocerse que los esfuerzos han logrado que el producto nacional llegue a 20 países, entre los que destacan principalmente, Estados Unidos, Canadá, Irlanda, Japón, Francia y Alemania, que en conjunto representan $68 \%$ del valor total de exportación. Es preciso destacar que este producto compite mediante la calidad, denominado vino Premium, ello lo respaldan más de 300 premios (González y Fuentes, 2013; Ruiz, 2014).

En líneas generales, la industria vitivinícola de México cuenta con una serie de fortalezas y oportunidades, tales como: alta calidad de los vinos (González y Fuentes, 2013); posibilidades de expansión de la superficie sembrada ya que sólo se utiliza $33.6 \%$ de su capacidad (Ruiz, 2014); cultura emprendedora de nuevos empresarios y la relación del sector con otras actividades primarias (acuícola, olivarera y quesera), y de servicios (restaurantes, hoteles y de turismo); oferta de cursos de capacitación por parte del gobierno (SEDECO, SAGARPA, SEFOA y SECTURE ${ }^{3}$ ) e instituciones académicas (UABC, CICESE y COLEF ${ }^{4}$ ) (Celaya, 2014); aumento de las ventas mediante el comercio electrónico en las páginas Web de las empresas (López y Sotelo, 2014); y, tradición vitícola arraigada al siglo XVII con la llegada de los misioneros a la Península de Baja California (Mac Kay, 2014).

De forma opuesta, hay varios factores que se traducen en amenazas y debilidades para el sector, por mencionar algunos: existencia de 2,000 etiquetas de las cuales 1,200 son de vinos importados; falta de cultura por el consumo de vino dado que hay mayor preferencia por la cerveza y gaseosas (Instituto Español de Comercio Exterior, 2012); necesidad de créditos accesibles para las micro y pequeñas empresas que promueva la cooperación en red, los encadenamientos intersectoriales y disponer de canales de

\footnotetext{
${ }^{1}$ HORECA es el acrónimo de Hoteles, Restaurantes y Cafetería.

${ }^{2}$ DO significa Denominación de Origen, siendo un distintivo de calidad, en este caso del vino español.

3 Secretaría de Desarrollo Económico; Secretaría de Agricultura, Ganadería, Desarrollo Rural, Pesca y Alimentación; Secretaría de Fomento Agropecuario; y Secretaría de Turismo del Estado de Baja California.

${ }^{4}$ Universidad Autónoma de Baja California, Centro de Investigación Científica y de Educación Superior de Ensenada, y Colegio de la Frontera Norte.
} 
distribución; competencia desigual con los vinos importados de Europa y Latinoamérica ya que disfrutan de subvenciones que no posee el producto nacional; alto costo del vino mexicano al ser entre $120 \%$ y $220 \%$ más caro al agravarse con un impuesto (IVA/IEPS ${ }^{5}$ ) que incrementa su precio en un 36\% (Ruiz, 2014); y poca disponibilidad de agua en los valles vitivinícolas (Valderrama y Meraz, 2012).

En este sentido, el titular de la Secretaría de Turismo, Enrique de la Madrid Cordero, en la Sexta Reunión de Ministros de Turismo del Grupo de los Veinte, enfatizó el valor de la actividad turística en México como detonante del crecimiento económico, generador de empleo digno, y fuente de posibilidad para las pequeñas y medianas empresas. Diciendo que "el turismo es un importante generador de empleos, no solamente que provee un buen nivel de ingreso, sino que sea de calidad y que dé un trato digno como mexicano. Me parece que la palabra de un empleo digno dice mucho sobre el tipo de empleo que queremos tener en nuestro país" (Secretaría de Turismo, 2015).

Recapitulando lo ya mencionado, la conformación del enoturismo en el país luce como una estrategia pertinente, la cual se ha ido favoreciendo como resultado de las rutas del vino, especialmente las de Baja California (en 2000, que incluye un corredor turístico de Tijuana-Rosarito-Ensenada y los valles de Guadalupe, Santo Tomás, San Vicente y Ojos Negros) donde se encuentra la mayor proliferación de MIPYMES, y Querétaro (entre 2008 y 2009, la que se extiende por los municipios de San Juan del Río, Ezequiel Montes, Bernal y Tequisquiapan), en las que se ha puesto en valor la cultura, el ambiente, la gastronomía y el vino, que potencian el aprovechamiento de los recursos existentes (Alpizar y Maldonado, 2009; González y Fuentes, 2013; Quiñónez et al., 2012).

La región vitivinícola de Baja California se encuentra al norte colindada con California, Estados Unidos, y es la zona con mayor nivel productivo de vino del país (Trejo-Pech et al., 2010). De acuerdo con la Secretaría de Turismo del Estado de Baja California (2014a), en el estado se recibe una afluencia de 160 mil visitantes al año a quienes se ofrecen 27 hoteles y 42 restaurantes con alta cocina y tradicional, así como cinco tiendas de autoservicios y 6 operadoras turísticas (Celaya, 2014). Aquí converge un triángulo de acontecimientos que incluyen vino, gastronomía y eventos artísticos, lo que ha generado la creación de nuevas fuentes de empleo, como lo resalta Cavazos (2012: p. 18):

"La Ruta del Vino en la carretera Ensenada-Tecate, desde San Antonio de las Minas hasta el Valle de Guadalupe, es donde se concentra la mayoría de las casas vitivinícolas. Sin embargo, en años recientes los vitivinicultores del sur de Ensenada, desde Santo Tomás a San Vicente han empezado a promocionar la llamada Antigua Ruta del Vino, y más recientemente los viticultores de Tecate empezaron a desarrollar lo que ellos llaman la Puerta Norte de la Ruta del Vino. Igualmente los productores en el Valle de Ojos Negros hacen festividades en colaboración con los productores de quesos de Real del Castillo, distinguiéndose la Cava de Marcelo, donde se producen quesos de alta calidad.»

Por otro lado, en Querétaro se han emprendido diversas actividades propias del enoturismo como recorridos por las bodegas Freixenet y La redonda, donde se lleva a cabo

\footnotetext{
${ }^{5}$ Impuesto al Valor Agregado e Impuesto Especial sobre Producción y Servicios.
} 
las festividades de la vendimia en agosto, que además incluye un paseo por el Pueblo Mágico de Bernal ${ }^{6}$, coincidiendo con el turismo de aventura. La mayor ventaja de esa área es que se encuentra muy cerca del Distrito Federal, siendo su principal mercado. La infraestructura hotelera se compone de 57 hoteles que ofertan 1,888 habitaciones, con una pernoctación aproximada de 2.2 días.

Adicionalmente, es preciso destacar que, como afirman los autores Ruiz et al. (2011: p. 147), "las casas productoras de vino cuentan con páginas de Internet en las que se ofrece información más específica y en las que se pueden contratar servicios complementarios a la vista a los viñedos", y que también las emplean para proporcionar información referente a "el_origen del viñedo productor, la marca, el tipo de uva utilizada, el año de la cosecha, si ha sido acreedor a premios o distinciones especiales y la dirección de la casa productora, así como información para contactarles en caso de requerir más información". Precisamente se realza el alto valor competitivo que tiene el uso de las tecnologías de la información y la comunicación en el sector del vino como factores detonantes del crecimiento económico y el aumento en la productividad (Campo et al., 2008; Lampón y Martínez, 2005; Liberman et al., 2009; Maldonado et al., 2010).

En general, "el turismo enológico y de enfoque cultural más diverso forma parte de las actividades económicas con mayor potencial en el norte de México" (González y Fuentes, 2013: p. 59). Pero, en definitiva, los enoturistas en el país cuentan una experiencia llena de elementos históricos, culturales y arqueológicos (Alpizar y Maldonado, 2009). Al igual que de productos adheridos a la gastronomía local (chorizos, quesos, pasteles, panes, tacos, empanadas, mermeladas, cerveza artesanal, entre otros) y demás sabores que se arraigan a las historias de las comunidades indígenas kumiai, misional y de los rusos molokanes. También se pueden realizar recorridos en bicicleta, paseos en globo, camping, paseos a caballo, rutas en automóviles tipo Off Road, y asistir a una gran variedad de eventos entorno al vino (Espejel et al., 2014; Quiñónez et al., 2012). Basado en la literatura citada se crea la siguiente hipótesis:

H: la competitividad de las regiones vitivinícolas se debe a sus elementos de valor.

Pese a toda la amplia oferta de productos y servicios por parte de las empresas que yacen en las zonas vitivinícolas de Baja California, no cuentan con un modelo claro ni un registro en cuanto a información estadística que permita a los funcionarios, empresarios y académicos contar con una base completa, sólida y unificada, que documente a través de un programa de datos la obtención de estadística de la actividad turística de esta región, que aborda el sector turismo en México, específicamente a las zonas vitivinícolas de Baja California. En este sentido, el Plan Nacional de Desarrollo 2013-2018 indica a través de sus objetivos 3.5, que es importante "Hacer del desarrollo científico, tecnológico y la innovación pilares para el progreso económico y social sostenible", y 4.11 "Aprovechar el potencial turístico de México para generar una mayor derrama económica en el país"; lo que a su vez reafirma la exigencia de la actual política turística del Gobierno Federal en pro del continuo

\footnotetext{
${ }^{6}$ Según la SECTUR en Treviño et al. (2015: p. 3) “Un Pueblo Mágico es una localidad que tiene atributos simbólicos, leyendas, historias, hechos trascendentes, cotidianidad, en fin magia que emana en cada una de sus manifestaciones socio - culturales, y que significan hoy en día una gran oportunidad para el aprovechamiento turístico".
} 
aumento de la competitividad de los destinos turísticos del país, de manera que se aprovechen los avances tecnológicos y de comunicación existentes y se beneficie a los distintos sectores y subsectores (público y privado), promoviendo la toma de decisiones e implementación de políticas públicas del turismo en el país, y al mismo tiempo se favorezca la demanda nacional 3. Generación de información estadística, particularmente en los siguientes puntos: (i) Sistemas de información turística de destinos, (ii) Estadísticas de productos turísticos, (iv) Desarrollo de programas para gestión de conocimiento en el tratamiento de datos para generación de estadísticas de la actividad turística, y (v) Cultura estadística.

\section{METODOLOGÍA}

Este estudio surge como resultado de una investigación doctoral concluida en enero de 2014, en la Universidad Autónoma de Baja California, México. En donde se analizó la correlación existente entre la oferta de actividades de enoturismo y la competitividad de las micro, pequeñas y medianas empresas vinícolas ubicadas en la Ruta del Vino del Valle de Guadalupe, obteniéndose una correlación débil (Hernández et al., 2010, p. 312) entre ambas mediante el análisis estadístico (Tabla 1), donde además el diagrama de puntos deja ver la falta de una relación lineal significativa (Figura 1). Por ende, se propuso esta nueva investigación sustentada en un estudio comparativo que permita presentar soluciones a las discrepancias observadas, en la que se pueda definir el mejor método para la estimación más confiable y realista de la oferta de actividades de enoturismo de las vinícolas de Baja California.

Tabla 1. Correlación entre la oferta de actividades de enoturismo y la competitividad

\begin{tabular}{|l|c|c|c|}
\hline \multicolumn{1}{|c|}{ Pregunta de investigación } & Correlación Pearson & $\begin{array}{c}\text { Significancia } \\
\text { (bilateral) }\end{array}$ & $\mathbf{N}$ \\
\hline $\begin{array}{l}\text { ¿De qué manera se correlacionan la oferta de actividades de } \\
\text { enoturismo y la competitividad de las micro, pequeñas y } \\
\text { medianas empresas vinícolas de la Ruta del Vino del Valle de } \\
\text { Guadalupe? }\end{array}$ & 0.126 & 0.398 & 54 \\
\hline
\end{tabular}

Fuente: Meraz (2015), p. 282.

Con base en lo ya mencionado, se tomó en consideración la propuesta de Beverland (2000) concerniente al estudio del enoturismo en su tercera línea de investigación: la comparación de estudios de casos de diferentes áreas geográficas utilizando metodologías similares; y Mitchell y Hall (2006) en sus líneas de investigación uno: producto enoturístico, en la que se analiza la influencia entre el turismo y las empresas vinícolas dentro de un determinado contexto, haciendo hincapié en las festividades, las rutas turísticas y otras atracciones relacionadas al vino, y dos: enoturismo y desarrollo regional, se analiza el impacto socioeconómico entre el turismo y las zonas geográficas, incluyendo actividades restauranteras, hoteleras, de trabajo y artesanía local, ya que se trata de una actividad puramente vocacional del área al ser la principal región vitivinícola de México.

Así, para el desarrollo de la presente investigación se realizó una estancia posdoctoral en el Departamento de Economía y Empresa de la Universidad de La Rioja, en la ciudad de Logroño, España. Teniendo como investigador tutor al Dr. Agustín V. Ruiz Vega, quien se desempeña como Profesor de Tiempo Completo adscrito al Grupo de Investigación DAGON 
(Estrategias de Marketing, Comercio, Distribución y Consumo). Donde se efectuó un trabajo continuo (de 37.5 horas a la semana de acuerdo a la legislación española) y coordinado con las bodegas de Baja California y La Rioja.

Figura 1. Diagrama de dispersión entre variables

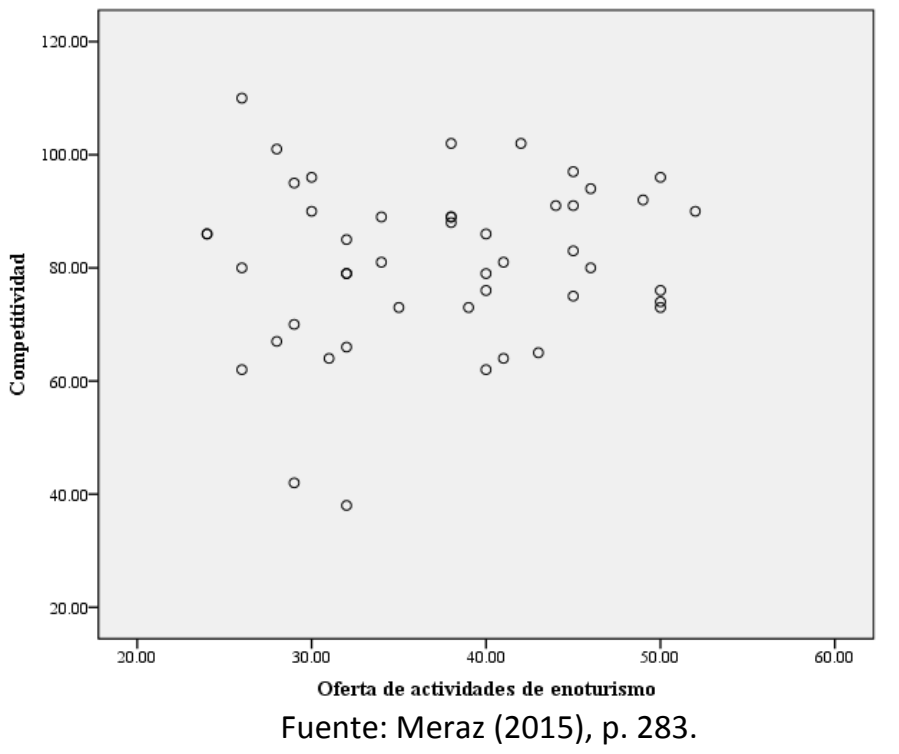

Durante este período se hizo una revisión bibliográfica del enoturismo y el sector del vino de La Rioja en España (Barco, 2012; Cabello y Pascual, 2015; Consejo Regulador de la Denominación de Origen Calificada Rioja, 2013; Instituto de Estadística de La Rioja, 2014; Instituto de Turismo de España, 2014; Ruiz et al., 2013). Posteriormente, se llevó a cabo la observación directa participativa mediante la visita a 10 bodegas localizadas en la ciudad de Logroño, del 7 de agosto al 26 de septiembre de 2015 (Tabla 2), como parte de la oferta enoturística que promueven estas vinícolas (Figuras 2, 3 y 4) (Ruiz y Pelegrín, 2011), lo que permitió conocer más acerca de la dinámica empresarial y territorial de esta Comunidad Autónoma.

Como dato general, es importante precisar que La Rioja se encuentra al norte de la Península Ibérica, siendo una de las 17 Comunidades Autónomas del Estado Español, caracterizada por ser la más pequeña, concretamente con una superficie de $5.045 \mathrm{~km}^{2}$. Está dividida en 174 municipios, en la que se ubican 315.223 habitantes, teniendo a Logroño como la capital, la cual colinda con el valle del Ebro y el Sistema Ibérico montañoso (Instituto de Estadística de La Rioja, 2014). Como productos representativos de este territorio son los vinos de La Rioja, los cuales están amparados por la Denominación de Origen más antigua de España, reconocida oficialmente el 6 de junio de 1925, ostentando la categoría máxima "Calificada" y amparada por un Consejo Regulador (1991). La geografía de producción incluye las Comunidades Autónomas de La Rioja, País Vasco (Álava) y Navarra (Figura 5), e incluso una pequeña área de Burgos, Castilla-León (Consejo Regulador de la Denominación de Origen Calificada Rioja, 2013; Ruiz et al., 2013).

Si bien, cabe entender que la actividad turística en La Rioja ha sido poco estudiada, pero se sabe que está en una etapa de inicio, ya que tiene pocos años que ha comenzado a detonarse gracias a la localidad de Ezcaray y su estación de esquí (Valdezcaray), sin 
menospreciar el éxito turístico del Camino de Santiago. No obstante, esta dinámica económica se ha visto favorecida por el enoturismo como consecuencia del turismo de interior de sus zonas vitivinícolas asociado al turismo rural por la oferta turística riojana. Dicha oferta incluye distintos actores como "promotores, restauradores, hoteleros, propietarios de alojamientos turísticos, bodegas, etc." (Cabello y Pascual, 2015: p. 35).

De esta manera, (i) se identificó el modelo de enoturismo de las zonas vitivinícolas de Baja California, el cual se integra por la oferta de productos (tales como el vino y otros productos artesanales) y servicios (como la gastronomía, hostelería y actividades artísticas adjuntas). Registrándose una base datos completa de las empresas que ofertan enoturismo en los valles vitivinícolas de Baja California, siendo no solamente bodegas sino también hoteles, restaurantes y promotores turísticos. También, (ii) se tomó una muestra de 64 empresas vinícolas de la Ruta del Vino del Valle de Guadalupe para obtener información respecto al tamaño, siendo en su mayoría de tamaño micro, pequeñas y medianas.

Tabla 2. Bodegas visitadas como parte la oferta enoturística en Logroño, La Rioja

\begin{tabular}{|c|c|c|c|}
\hline No. & Bodegas & Visita & Sitio web \\
\hline 1 & Bodegas Olarra & 7 / agosto / 2015 & $\begin{array}{l}\text { http://www.grupobodegasolarra.com/es/acceso } \\
\text { /home }\end{array}$ \\
\hline 2 & $\begin{array}{l}\text { Bodegas Franco } \\
\text { Españolas }\end{array}$ & 8 / agosto / 2015 & http://francoespanolas.com/ \\
\hline 3 & Bodegas Campo Viejo & 15 / agosto / 2015 & http://www.campoviejo.com/ \\
\hline 4 & Bodegas Ontañón & 28 / agosto / 2015 & http://ontanon.es/en/ \\
\hline 5 & Marqués de Murrieta & 5 / septiembre / 2015 & http://www.marquesdemurrieta.com/web/es/ \\
\hline 6 & Viña ljalba & 11 / septiembre / 2015 & http://ijalba.com/ \\
\hline 7 & $\begin{array}{l}\text { Bodegas del Marqués de } \\
\text { Vargas }\end{array}$ & 12 / septiembre / 2015 & http://www.marquesdevargas.com/es/ \\
\hline 8 & Bodegas Darien & 25 / septiembre / 2015 & http://wws.darien.es/ \\
\hline 9 & Bodega Valoria & 25 / septiembre / 2015 & http://www.bvaloria.com/ \\
\hline 10 & Bodegas Faustino & 26 / septiembre / 2015 & http://www.bodegasfaustino.com/ \\
\hline
\end{tabular}

Fuente: Elaboración propia. 
Figuras 2, 3 y 4. Recorrido enoturístico en Logroño, La Rioja
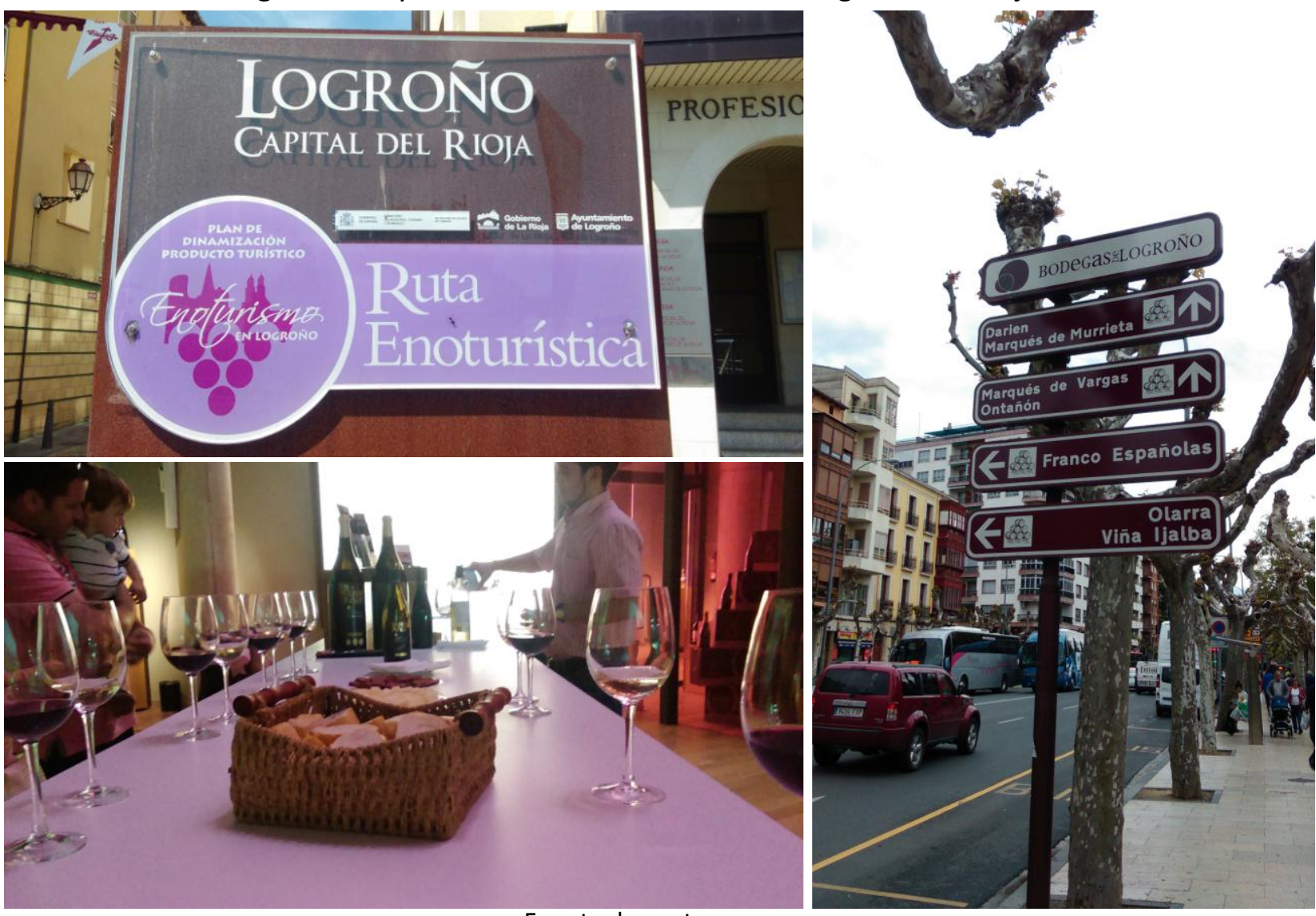

Fuente: los autores.

Figura 5. Mapa de La Rioja, España (2015)

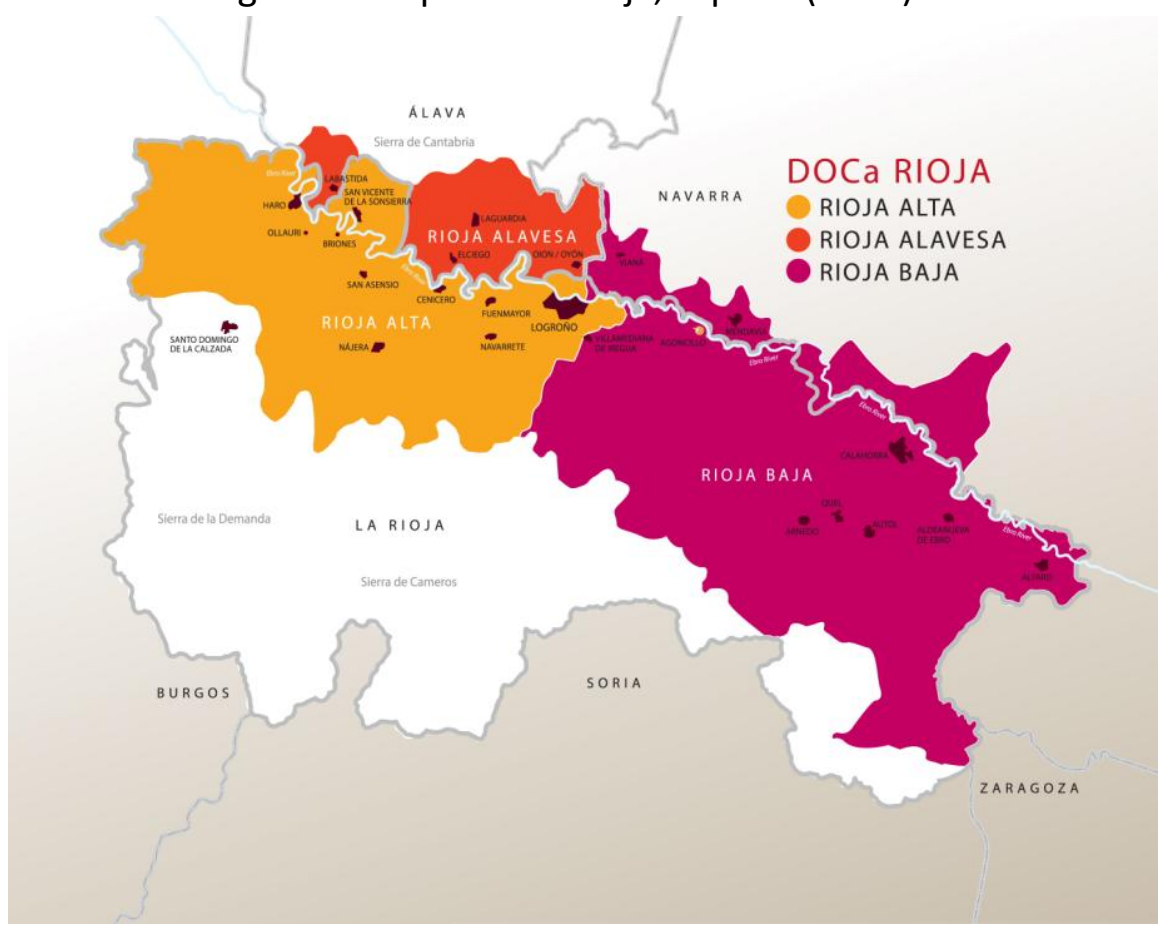

Fuente: Consejo Regulador de la Denominación de Origen Rioja. 


\section{RESULTADOS}

La observación directa participativa en las 10 bodegas de Logroño, La Rioja, permitió conocer y contrastar la oferta enoturística existente en la zona. Se percibió una amplia cultura vitivinícola, tanto por productores como consumidores. Todas las visitas guiadas y catas didácticas son de fácil acceso mediante la compra electrónica de un ticket por internet que va de 5 a 20 euros. Además, el vino es considerado como un complemento alimenticio que perfectamente puede ser acompañado por un "pincho" o "tapa" (Figuras 6 y 7).

Figuras 6 y 7. Vinos y tapas de La Rioja
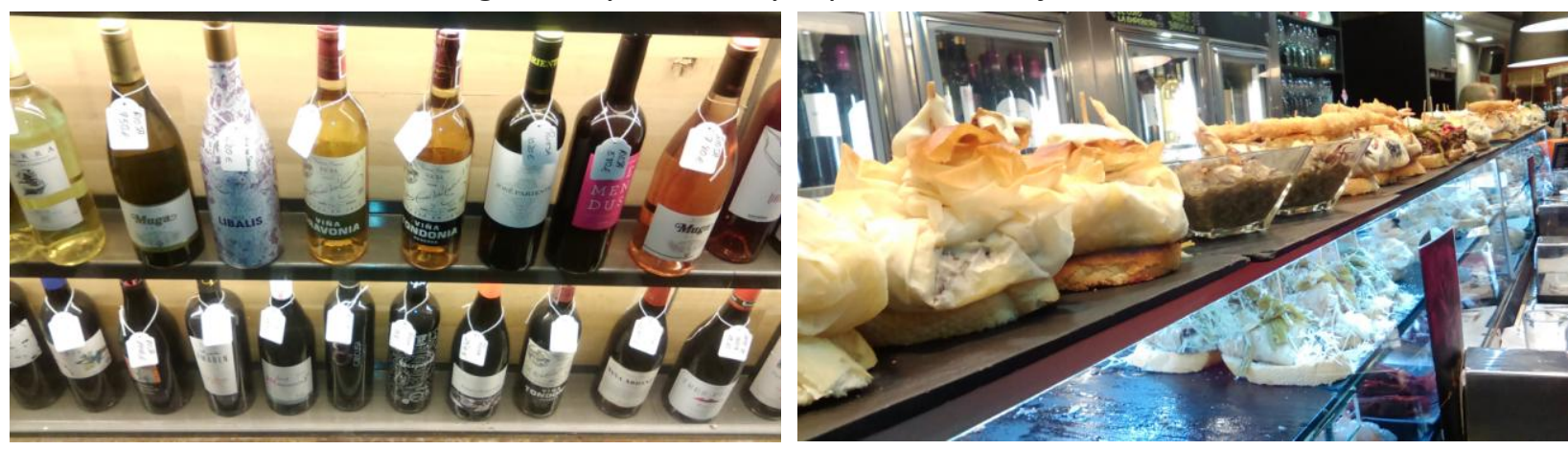

Fuente: los autores.

Durante las fiestas de la vendimia en Logroño (fiestas de San Mateo) se desarrollan distintas actividades, tales como catas de vino y aceites de oliva, bendición y pisado de uva en la Plaza del Espolón, maridajes en la Calle Laurel, desfiles sobre la Calle Portales, disparo del cohete o "chupinazo", pasarela de los gigantes cabezudos, chamizos y quema de la cuba, batallas medievales representativas, recorridos guiados por los antiguos calados y el museo del vino (Centro de la Cultura del Rioja), actuaciones y teatro (Brentón), tauromaquia, así como otras fiestas de menor tamaño en los pueblos de Agoncillo, Najera, Santo Domingo y Ezcaray.

\subsection{Desarrollo del modelo de enoturismo}

Se identificó que el modelo de enoturismo de las zonas vitivinícolas de Baja California se conjuga en la oferta de productos y servicios por parte de promotores, restauradores, hoteleros o propietarios de alojamientos turísticos, y bodegas, abarcando las cuatro rutas del vino: Ruta del Vino del Valle de Guadalupe (poblados de San Antonio de las Minas, Guadalupe, Francisco Zarco, El Porvenir, San Marcos, El Sauzal y El Tigre) (Figura 8), Antigua Ruta del Vino (valles de La Grulla, Santo Tomás y San Vicente), Puerta Norte a la Ruta del Vino (Valle de Tanamá y Valle de Las Palmas, en la ciudad de Tecate), y Ruta Vinícola de Ojos Negros (valle de Ojos Negros).

Dentro de este modelo se registró la existencia de 20 promotores, 50 restaurantes, 27 hoteles y 95 bodegas, siendo en su totalidad 192 establecimientos que ofrecen enoturismo (Tabla 3). La distribución de dicha oferta se desglosa a continuación: en la Ruta del Vino del Valle de Guadalupe existen 80 bodegas (Tabla 4), 23 hoteles y 46 restaurantes (Tabla 5); en la Antigua Ruta del Vino hay 8 bodegas, 2 hoteles y 2 restaurantes (Tabla 6); la Puerta Norte a la Ruta del Vino registra 6 bodegas, 2 hoteles y 1 restaurante (Tabla 7); y, 
finalmente, la Ruta Vinícola de Ojos Negros cuenta con 1 bodegas, cero hoteles y 1 restaurante (Tabla 8).

Tabla 3. Población de empresas que ofrecen enoturismo en Baja California

\begin{tabular}{|c|c|c|c|c|c|}
\hline Ruta & Valles/Poblado & Promotores & Restaurantes & Hoteles & Bodegas \\
\hline \multirow{6}{*}{$\begin{array}{l}\text { Ruta del Vino } \\
\text { del Valle de } \\
\text { Guadalupe }\end{array}$} & San Antonio de las Minas & \multirow[t]{12}{*}{20} & \multirow[t]{6}{*}{46} & \multirow[t]{6}{*}{23} & \multirow[t]{6}{*}{80} \\
\hline & Francisco Zarco & & & & \\
\hline & El Porvenir & & & & \\
\hline & San Marcos & & & & \\
\hline & El Sauzal & & & & \\
\hline & El Tigre & & & & \\
\hline \multirow{3}{*}{$\begin{array}{l}\text { Antigua Ruta } \\
\text { del Vino }\end{array}$} & La Grulla & & \multirow[t]{3}{*}{2} & \multirow[t]{3}{*}{2} & \multirow[t]{3}{*}{8} \\
\hline & Santo Tomás & & & & \\
\hline & San Vicente & & & & \\
\hline \multirow{2}{*}{$\begin{array}{l}\text { Puerta Norte a } \\
\text { la Ruta del Vino }\end{array}$} & Tanamá & & \multirow[t]{2}{*}{1} & \multirow[t]{2}{*}{2} & \multirow[t]{2}{*}{6} \\
\hline & Las Palmas & & & & \\
\hline $\begin{array}{l}\text { Ruta Vinícola de } \\
\text { Ojos Negros }\end{array}$ & Ojos Negros & & 1 & 0 & 1 \\
\hline & Total: & 20 & 50 & 27 & 95 \\
\hline
\end{tabular}

Fuente: Elaboración propia con base en Meraz (2015), SECTURE (2011, 2014b).

La elaboración de la base de datos con que actualmente se dispone fue construida de tres registros publicados: el primero, un folleto de la Secretaría de Turismo del Estado de Baja California (2011); el segundo, el mismo pero en su versión actualizada (2014); y el tercero, una muestra de estudio de una investigación doctoral del propio autor (Meraz, 2015). De esta manera, el registro de empresas (promotores, restaurantes, hoteles y bodegas) se completó evitando dejar de lado alguna empresa que pudiera ser valiosa en cuanto a su oferta de productos y servicios. 
Figura 8. Ruta del Vino del Valle de Guadalupe

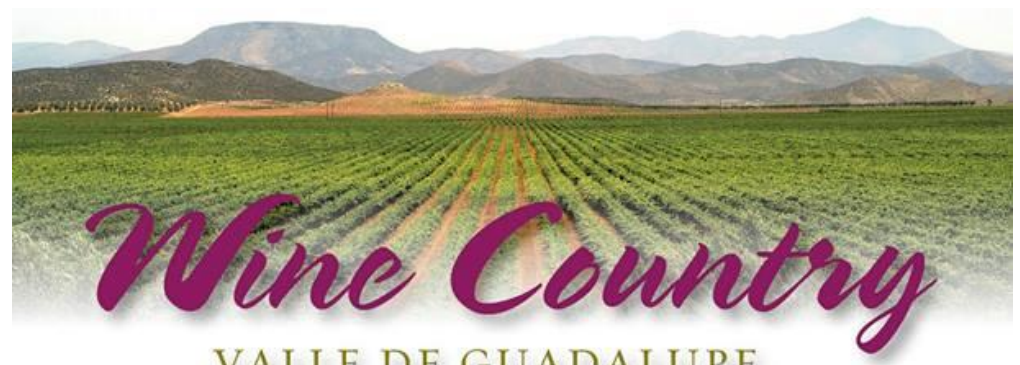

\section{VALLE DE GUADALUPE}

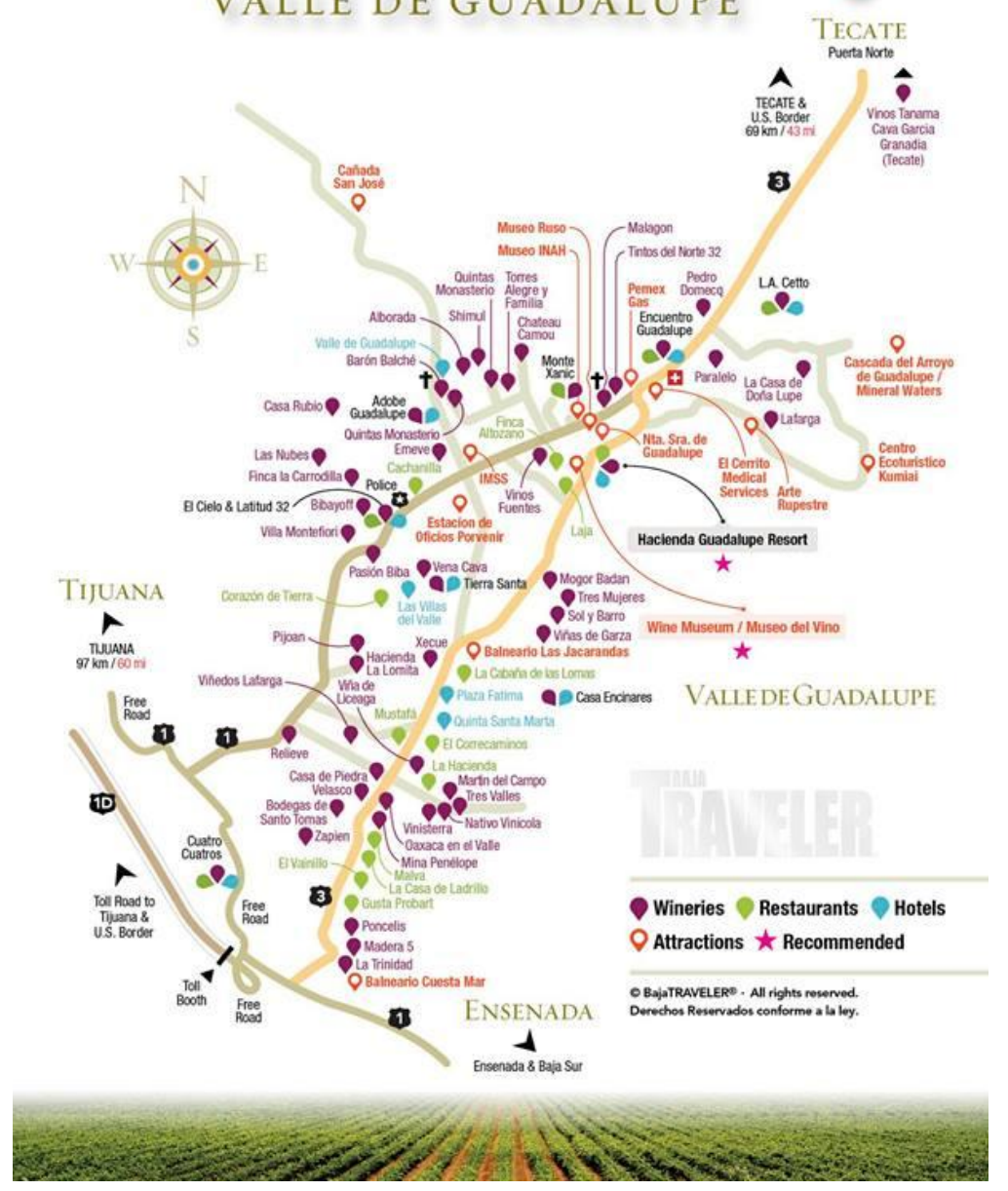

Fuente: Baja Traveler Guide (2014), p. 52. 
Tabla 4. Bodegas en la Ruta del Vino del Valle de Guadalupe

\begin{tabular}{|c|c|c|c|}
\hline No. & Vinícolas & No. & Vinícolas \\
\hline 1 & Aborigen & 41 & Malagón \\
\hline 2 & Adobe Guadalupe & 42 & Martín del Campo \\
\hline 3 & Alborada & 43 & Mina Penelope \\
\hline 4 & Alximia & 44 & Misión California \\
\hline 5 & Aragón 126 & 45 & Mogor Badán \\
\hline 6 & Arcilla & 46 & Monte Xanic \\
\hline 7 & Barón Balché & 47 & Nativo Vinícola \\
\hline 8 & Bibayoff & 48 & Norte 32 \\
\hline 9 & Bodegas Carmadi & 49 & Paralelo \\
\hline 10 & Boutique Entre Santos & 50 & Pasión Biba \\
\hline 11 & Casa de Piedra & 51 & Pijoán \\
\hline 12 & Casa Encinares & 52 & Quinta Lizárraga \\
\hline 13 & Casta de Vinos & 53 & Quinta Monasterio \\
\hline 14 & Cava Mora & 54 & Relieve \\
\hline 15 & Chateau Camou & 55 & Retorno \\
\hline 16 & Clos de Tres Cantos & 56 & Rondo del Valle \\
\hline 17 & Cuatro Cuatros & 57 & San Miguel \\
\hline 18 & De Garza & 58 & Santa Ursula \\
\hline 19 & Don Juan Vinícolan - Vinos Sueños & 59 & Santana \\
\hline 20 & El Cielo & 60 & Shedeh \\
\hline 21 & Emevé & 61 & Shimul \\
\hline 22 & Encuentro Guadalupe & 62 & Sol de Media Noche \\
\hline 23 & Fratelli Pasini & 63 & Sol y Barro \\
\hline 24 & F. Rubio & 64 & Torres Alegre y Familia \\
\hline 25 & Finca La Corradilla & 65 & Tres Mujeres \\
\hline 26 & Firmamento & 66 & Tres Valles \\
\hline 27 & Fuentes & 67 & Trevista \\
\hline 28 & Gran Rosario 1979 Wine Lounge & 68 & Trinidad \\
\hline 29 & Hacienda La Cava Boutique & 69 & Velasco \\
\hline 30 & Hacienda La Lomita & 70 & Vena Cava \\
\hline 31 & Hilo Negro & 71 & Villa Montefiori \\
\hline 32 & J. C. Bravo & 72 & Vinícola Fraternidad \\
\hline 33 & La Casa de Doña Lupe & 73 & Vinisterra \\
\hline 34 & La Casa Vieja & 74 & Vino de la Reina \\
\hline 35 & L.A. Cetto & 75 & Viñas de la Erre \\
\hline 36 & Lafarga & 76 & Viñas del Tigre \\
\hline 37 & Las Nubes & 77 & Viñas Tierra Santa \\
\hline 38 & Legado Sais & 78 & Viñedos Lechuza \\
\hline 39 & Liceaga & 79 & Xecue \\
\hline 40 & Maglen & 80 & Zapien \\
\hline
\end{tabular}

Fuente: Elaboración propia con base en Meraz (2015), SECTURE (2011, 2014b). 
Tabla 5. Hoteles y restaurantes en la Ruta del Vino del Valle de Guadalupe

\begin{tabular}{|c|c|c|c|}
\hline No. & Hoteles & No. & Hoteles \\
\hline 1 & Adobe Guadalupe & 13 & Rancho El Parral Hotel \& Viñedo \\
\hline 2 & Baja Racho la Bellota & 14 & Plaza Fátima \\
\hline 3 & Casa Encinares & 15 & Posada Inn Misión de Guadalupe \\
\hline 4 & Cuatro Cuatros & 16 & Quinta Bugambilias \\
\hline 5 & Encuentro Guadalupe & 17 & Quinta Casa Blanca \\
\hline 6 & Finca Koochaege & 18 & Quinta Las Margaritas B \& B \\
\hline 7 & $\begin{array}{l}\text { Hacienda Guadalupe Hotel y } \\
\text { Restaurante }\end{array}$ & 19 & Tierra del Valle Bed \& Breakfast \\
\hline 8 & Hotel Boutique Valle de Guadalupe & 20 & Tesela Hotel \\
\hline 9 & La Villa del Valle & 21 & Villas Maglen \\
\hline 10 & Malagón & 22 & Villas Tierra Santa \\
\hline 11 & Mesón del Vino & 23 & Villas del Tigre \\
\hline 12 & $\begin{array}{l}\text { Misión Santa Cristina Cabañas \& } \\
\text { Relajación }\end{array}$ & & \\
\hline No. & Restaurantes & No. & Restaurantes \\
\hline 1 & Allegro Burguers \& Grill & 24 & La Casa de Doña Lupe \\
\hline 2 & Almazara Gastro Bar & 25 & La Esperanza \\
\hline 3 & Antique Postres y Bistro & 26 & La Terrase San Román \\
\hline 4 & Bistro La Grange & 27 & Laja \\
\hline 5 & Cabañas de Las Lomas & 28 & Latitud 32 \\
\hline 6 & Cachanilla & 29 & Leonardo's \\
\hline 7 & Casa Antara & 30 & Los Naranjos \\
\hline 8 & Cocina de Doña Esthela & 31 & Lozhka Bistrot de Cocina Local \\
\hline 9 & Cocina Rusa Familia Samarín & 32 & Malva \\
\hline 10 & Convivia & 33 & Manzana Verde \\
\hline 11 & Comedor Campestre Traslomita & 34 & Mustafá \\
\hline 12 & Corazón de Tierra & 35 & Nuestra Cava \\
\hline 13 & Correcaminos & 36 & Ochentos Pizzas \\
\hline 14 & Deckman's en el Mogor & 37 & Origen \\
\hline 15 & $\begin{array}{l}\text { El Pinar de Tres Mujeres (Cocina de } \\
\text { Ismene) }\end{array}$ & 38 & Quercus \\
\hline 16 & Finca Altozano & 39 & Quinta Las Margaritas B \& B \\
\hline 17 & Francelia Café & 40 & ROA'S \\
\hline 18 & Fuego Restaurante \& Lounge & 41 & Ruta 97 \\
\hline 19 & Gaucho & 42 & Samiento's \\
\hline 20 & Ha Che & 43 & Silvestre \\
\hline 21 & $\begin{array}{l}\text { Hacienda Guadalupe Hotel y } \\
\text { Restaurante }\end{array}$ & 44 & Tahal Cocina + Vino \\
\hline 22 & Hacienda Restaurante y Vivero & 45 & Tre Galline \\
\hline 23 & La Cabaña & 46 & Vinos de la Ruta \\
\hline
\end{tabular}

Fuente: Elaboración propia con base en SECTURE (2011, 2014b). 
Tabla 6. Bodegas, hoteles y restaurantes en la Antigua Ruta del Vino

\begin{tabular}{|c|c|c|c|}
\hline No. & Vinícolas & No. & Vinícolas \\
\hline 1 & Aldo César Palafox & 5 & Santo Domingo \\
\hline 2 & Cava Antigua Ruta del Vino & 6 & Santo Tomás \\
\hline 3 & M.D. Vinos & 7 & Villarino \\
\hline 4 & Rincón de Guadalupe & 8 & Vinos Dubacano \\
\hline \multicolumn{2}{|r|}{ No. } & \multicolumn{2}{|r|}{ Hoteles } \\
\hline \multicolumn{2}{|l|}{1} & \multicolumn{2}{|c|}{ El Palomar } \\
\hline \multicolumn{2}{|l|}{2} & \multicolumn{2}{|c|}{ Posada de La Grulla } \\
\hline \multicolumn{2}{|r|}{ No. } & \multicolumn{2}{|r|}{ Restaurantes } \\
\hline \multicolumn{2}{|l|}{1} & \multicolumn{2}{|c|}{ El Palomar } \\
\hline \multicolumn{2}{|r|}{2} & \multicolumn{2}{|r|}{ Zarcillo } \\
\hline
\end{tabular}

Fuente: Elaboración propia con base en SECTURE (2011, 2014b).

Tabla 7. Bodegas, hoteles y restaurantes en la Puerta Norte a la Ruta del Vino

\begin{tabular}{|c|c|c|c|}
\hline No. & Vinícolas & No. & Vinícolas \\
\hline 1 & Atmósfera 16 & 4 & Granadia - Rancho Las Karinas \\
\hline 2 & Cava García & 5 & Tanamá \\
\hline 3 & Don Juan Viñedos & 6 & San Rafael (Ojos Negros) \\
\hline \multicolumn{2}{|r|}{ No. } & \multicolumn{2}{|r|}{ Hoteles } \\
\hline \multicolumn{2}{|l|}{1} & \multicolumn{2}{|c|}{ Rancho Tecate } \\
\hline \multicolumn{2}{|l|}{2} & \multicolumn{2}{|c|}{ PENDIENTE } \\
\hline \multicolumn{2}{|r|}{ No. } & \multicolumn{2}{|r|}{ Restaurantes } \\
\hline \multicolumn{2}{|l|}{1} & \multicolumn{2}{|c|}{ Puerta Norte } \\
\hline
\end{tabular}

Fuente: Elaboración propia con base en SECTURE (2011, 2014b).

Tabla 8. Bodegas y restaurantes en la Ruta Vinícola de Ojos Negros

\begin{tabular}{|c|c|}
\hline No. & Vinícolas \\
\hline 1 & Bodegas San Rafael \\
\hline No. & Restaurantes \\
\hline 1 & Essencia Ojos Negros \\
\hline
\end{tabular}

Fuente: Elaboración propia con base en SECTURE (2011, 2014b).

\subsection{Caracterización de las empresas}

Para tener un conocimiento de las características de las empresas que ofertan enoturismo, se consideró la caracterización hecha por el propio autor en 2015, siendo de 64 bodegas ubicadas en la Ruta del Vino del Valle de Guadalupe (Tabla 9). En ella se indica que el $89 \%$ se dedican a la elaboración y venta de vino, y el $60 \%$ de forma alterna ofrecen otros productos y servicios, tales como la gastronomía y hospedaje. En cuanto al tamaño de las empresas, y considerando la clasificación establecida por el Banco Mundial en 2012 (Tabla 10), el $59.4 \%$ son micro, el $18.8 \%$ son pequeñas y el $10.9 \%$ son medianas (Figura 9 ). 
Tabla 9. Muestra para la caracterización

\begin{tabular}{|c|c|c|c|c|c|}
\hline No & Vinícolas & Ubicación & No & Vinícolas & Ubicación \\
\hline 1 & Adobe Guadalupe & Francisco Zarco & 33 & Sol de Medianoche & Francisco Zarco \\
\hline 2 & Alborada & El Porvenir & 34 & Sol y Barro & Valle de Guadalupe \\
\hline 3 & Alximia & Valle de Guadalupe & 35 & Tintos del Norte 32 & Francisco Zarco \\
\hline 4 & Arcilla & Valle de Guadalupe & 36 & Torres Alegre y Familia & El Porvenir \\
\hline 5 & Barón Balché & Francisco Zarco & 37 & Tres Mujeres & San Antonio de las Minas \\
\hline 6 & Bibayoff & El Tigre & 38 & Tres Valles & San Antonio de las Minas \\
\hline 7 & Bodegas de Santo Tomás & San Antonio de las Minas & 39 & Velasco & San Antonio de las Minas \\
\hline 8 & Casa de Piedra & San Antonio de las Minas & 40 & Vena Cava & Francisco Zarco \\
\hline 9 & Casa Encinares & San Antonio de las Minas & 41 & Villas Montefiori & El Porvenir \\
\hline 10 & Pernod Ricard México & Valle de Guadalupe & 42 & Villas Tierra Santa & Francisco Zarco \\
\hline 11 & Chateau Camou & Francisco Zarco & 43 & Vinícola Fraternidad & El Porvenir \\
\hline 12 & Cuatro Cuatros & El Tigre & 44 & Vinisterra & San Antonio de las Minas \\
\hline 13 & Emeve & El Porvenir & 45 & Vinos Fuentes & Valle de Guadalupe \\
\hline 14 & Encuentro Guadalupe & Valle de Guadalupe & 46 & Vinos Pasión Biba & Valle de Guadalupe \\
\hline 15 & $\begin{array}{l}\text { Hacienda La Cava } \\
\text { Boutique }\end{array}$ & Francisco Zarco & 47 & Vinos Sueños & Valle de Guadalupe \\
\hline 16 & Hacienda La Lomita & San Antonio de las Minas & 48 & Viña de Liceaga & San Antonio de las Minas \\
\hline 17 & J.C. Bravo & El Porvenir & 49 & Viñas del Tigre & El Tigre \\
\hline 18 & La Casa de Doña Lupe & Valle de Guadalupe & 50 & Viñas de Garza & Valle de Guadalupe \\
\hline 19 & L.A. Cetto & Valle de Guadalupe & 51 & Viñas Sais & Francisco Zarco \\
\hline 20 & Lafarga & Valle de Guadalupe & 52 & Viñas Tierra Santa & Francisco Zarco \\
\hline 21 & Las Nubes & El Porvenir & 53 & Xecue & San Antonio de las Minas \\
\hline 22 & Malagón & Francisco Zarco & 54 & Zapien & San Antonio de las Minas \\
\hline 23 & Martín del Campo & San Antonio de las Minas & 55 & La Casa Vieja & San Antonio de las Minas \\
\hline 24 & Mogor Badán & San Antonio de las Minas & 56 & Cava Aragón 126 & San Antonio de las Minas \\
\hline 25 & Monte Xanic & Francisco Zarco & 57 & Vinos y Villas Maglen & El Porvenir \\
\hline 26 & Nativo & San Antonio de las Minas & 58 & Bodegas Carmadi & San Antonio de las Minas \\
\hline 27 & Paralelo & Valle de Guadalupe & 59 & Viñedos Lechuza & Francisco Zarco \\
\hline 28 & Pijoan & San Antonio de las Minas & 60 & Quinta Lizárraga & San Antonio de las Minas \\
\hline 29 & Quinta Monasterio & El Porvenir & 61 & Viñedos de Santana & Francisco Zarco \\
\hline 30 & Relieve & San Antonio de las Minas & 62 & Rancho Rubio & El Porvenir \\
\hline 31 & Santa Úrsula & El Porvenir & 63 & Hacienda Guadalupe & Francisco Zarco \\
\hline 32 & Shimul & El Porvenir & 64 & San Miguel & El Porvenir \\
\hline
\end{tabular}
Fuente: Meraz (2015), p. 201.

Tabla 10. Clasificación de las micro, pequeñas y medianas empresas

\begin{tabular}{|l|l|l|l|}
\hline \multicolumn{1}{|c|}{ Tamaño } & \multicolumn{1}{c|}{ Empleados } & \multicolumn{1}{c|}{ Activos } & \multicolumn{1}{c|}{ Ventas } \\
\hline Micro empresa & 1 a 10 & 10,000 & 100,000 \\
\hline Pequeña empresa & 11 a 50 & $3,000,000$ & $3,000,000$ \\
\hline Mediana empresa & 51 a 300 & $15,000,000$ & $15,000,000$ \\
\hline
\end{tabular}

Fuente: Banco Mundial (2012). 
Figura 9. Tamaño de las vinícolas de la Ruta del Vino del Valle de Guadalupe

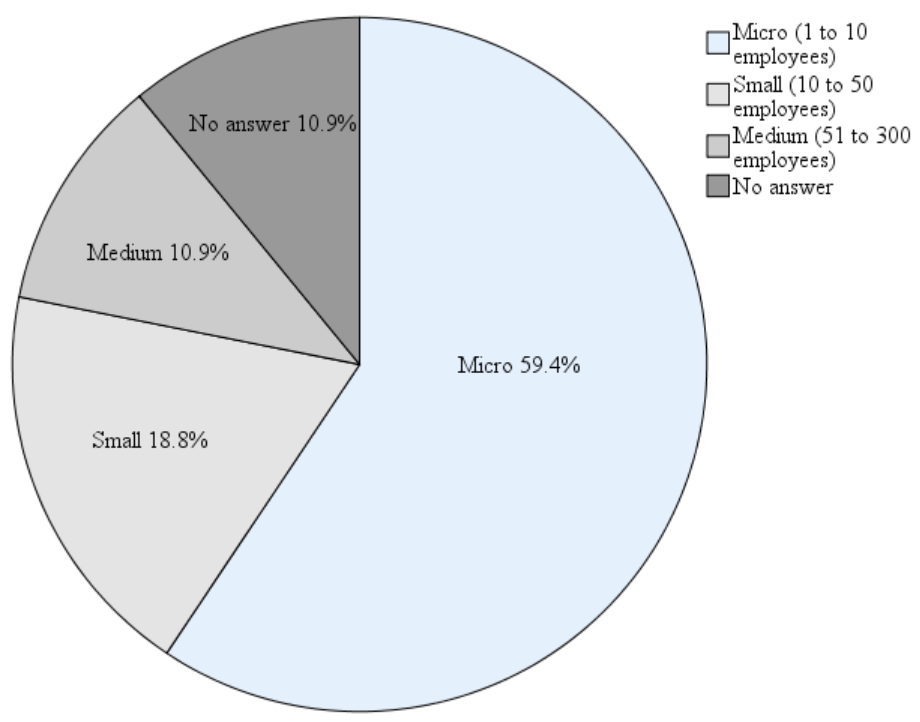

Fuente: Meraz (2015), p. 243.

A nivel global este conglomerado empresarial representa el $95 \%$ del total de las empresas (Moreno, 2011). En México suman el 99.1\%, las cuales generan el $60 \%$ del Producto Interno Bruto, el $7 \%$ de las exportaciones y el $70 \%$ del empleo formal. $Y$, en Baja California categorizan el $99.5 \%$. Simplificándose mayormente en empresas de tipo familiar (de ellas el $73.2 \%$ son familiares y $15.6 \%$ pertenecen a un grupo de socios), así lo afirman Velarde et al. (2011) en un estudio del uso de las tecnologías de la información en Coahuila, México.

\section{DISCUSIÓN Y CONCLUSIONES}

La reconfiguración del turismo y sus motivaciones ha vuelto a los viajeros a visitar regiones vitivinícolas, bodegas, festivales y recorridos guiados, prueba de ello es la apuesta de los empresarios y gobierno en mejorar la infraestructura, oferta y actividades que promuevan el consumo y conocimiento del vino. Por ello, en este trabajo se presentó el análisis de la oferta de enoturismo de Baja California y La Rioja, a través de la observación directa participativa mediante visitas a 10 bodegas en Logroño, La Rioja. Donde se pudo observar que la oferta de enoturismo es promovida por promotores, restaurantes, hoteles o alojamientos turísticos, y bodegas, de acuerdo a Cabello y Pascual (2015). Situación similar a la de Baja California, en la que el enoturismo es llevado acabo principalmente por bodegas, hoteles y restaurantes, pero también por promotores turísticos, especializados en el vino y la gastronomía, quienes se conjugan en 192 oferentes.

Partiendo de la bibliografía y del trabajo empírico, se identificó que la mayoría de las bodegas son de tamaño micro (59.4\%), acorde a una muestra de 64 empresas. Esta situación ha sido constante en regiones vitivinícolas que crecen y se desarrollan, soportadas en un esquema de organización de muy pocas empresas grandes y un puñado de micro empresarios que deben hacer frente a los altos costos de producción y venta, y a la imposición de un régimen fiscal que los limita por un lado, pero en contraparte los lleva a 
establecer lazos cooperativos de competitividad y competencia. Si bien, es cierto que existen grandes diferencias entre las zonas vitivinícolas de Baja California y La Rioja, particularmente de este último se destaca la presencia del antecedente histórico del hacer y vender vino, la cultura de comprar y consumir el producto (como alimento), la normativa actualmente vigente en España de la Viña y el Vino ${ }^{7}$, la gran producción y amplio número de bodegas amparadas en DO, DOC y vinos de pago ${ }^{8}$ (Ruiz y Riaño, 2011), así como la clasificación de productores de uva y vino establecidos de la DOC Rioja ${ }^{9}$ (Barco, 2008).

En el caso de Baja California, también se tiene una larga tradición de producción y consumo de bebidas alcohólicas, en especial tequila, cerveza y mezcal; la poca producción acerca del $25 \%$ se destina al mercado interno; la adquisición de insumos, como barriles, corchos y botellas, e infraestructura para vinificación son importados, siendo de alto costo para los pequeños productores; se carece de un consejo regulador que vele por los intereses de los productores, solamente se tiene del apoyo de algunas instituciones de gobierno que impulsan al sector a través de fondos y recursos económicos limitados (Trejo-Pech et al., 2012); etcétera. Por lo tanto, la hipótesis (H) no es posible comprobarla, dado que desde el enfoque cualitativo-descriptivo es complejo establecer parámetros de medida y comparación, pero se puede afirmar que en Baja California se debiera contar con otros elementos que identifiquen y generen un atractivo que posicione mayormente a los productos y el territorio en sí, por ejemplo, las marcas o varietales, como lo hace Chile con Carmenere y Argentina con Malbec. A su vez que también se genere un ambiente de colaboración y cooperación entre empresarios, lo que agrega valor a la cadena de producción y eleva el nivel de competitividad, sobre todo d las micro y pequeñas empresas.

La principal aplicación práctica de esta investigación es contribuir a la comprensión de que en ambas regiones, o al menos en Baja California, existe una infraestructura turística sobredimensionada que requiere atención y planificación. La abundancia de alojamientos, servicios de restauración y de recursos turísticos (enoturismo), particularmente en el medio rural, no obedecen a normas de planificación. Tampoco atienden a la heterogeneidad de las preferencias de los consumidores en cuanto a sus procesos de elección de la oferta enoturística (Charters y Ali-Knight, 2002; Colmenero, 2007). Justamente, en términos de sobredimensión, en años recientes se ha presentado un colapso entre el crecimiento de la industria vitivinícola, la oferta de espacios para pernoctar y de diversión (campo de golf y áreas para conciertos masivos), y la falta de un uso consciente de los recursos, especialmente en el Valle de Guadalupe, por lo que se sugiere establecer medidas preventivas y regulatorias que conlleven hacia un mejor control de lo que se produce y se tiene.

Ciertamente el tema del enoturismo en México no cuenta con suficientes estudios, pero existen esfuerzos aislados para apoyar y fomentar la actividad del turismo. Pero, se observa que uno de los principales problemas es que no hay suficientes turistas para tantos destinos, lo que reclama una ordenada planificación por parte de instituciones y agentes turísticos, sobre todo como base estadística para la toma de decisiones del sector turismo

\footnotetext{
${ }^{7}$ Que regula las marcas colectivas: vinos de pago, vinos con DO Calificada, vinos DO, vinos de calidad con Identificación Geográfica, vinos de la tierra, vinos de mesa con Identificación Geográfica y vinos de mesa. ${ }^{8}$ A fines de 2010 había 4,589 bodegas amparadas.

${ }^{9}$ (a) Viticultores no asociados y no elaboradores, (b) cosecheros, y (c) viticultores asociados de alguna cooperativa).
} 
del país. También resultará interesante conocer las nuevas iniciativas y medidas en gestión empresarial que han desarrollado en el tema del fomento al consumo y venta de vino, puesto que todavía se percibe un ambiente de rechazo en el uso de internet y el comercio electrónico. Así, pues, el conocimiento generado tras este proyecto será destinado en favor de la investigación científica, tecnológica y la innovación utilizado por la sociedad mexicana para su proceso de transformación, de desarrollo social y económico, lo cual resulta una pequeña pero importante aportación y muestra una o varias temáticas para futuras investigaciones.

Adicionalmente, según un comunicado de prensa del Boletín Turismo (2013: 19-20) de la Confederación de Cámaras Nacionales de Comercio, Servicios y Turismo en México, el turismo es de suma importancia en Querétaro y otros estados, ya que promueve la valoración y preservación de la riqueza natural y cultural, lo que a su vez "representa un poderoso instrumento para generar conocimiento y fortalecer el desarrollo económico de las regiones", así como el espíritu emprendedor de las micro, pequeñas y medianas empresas. Por lo que es preciso destacar también que el Estado de Querétaro goza de amplias oportunidades para detonar el turismo, al contar con cuatro recorridos que muestran su historia y naturaleza: Ruta de las Haciendas, Ruta del Semi-desierto, Ruta de la Sierra Gorda, y Ruta del Queso y el Vino (Figura 10). Esta última hace que sea reconocida como la segunda zona vitivinícola más importante del país; ruta que recorre los Pueblos Mágicos de Tequisquiapan y Bernal (Secretaría de Turismo del Estado de Querétaro, 2013).

En este sentido, como futura investigación se propone (i) continuar con el desarrollo del modelo enoturístico; (ii) presentar una caracterización de datos demográficos que englobe a todas las empresas que oferta enoturismo; (iii) generar una base de datos que sirva como registro completo y unificado de todas las empresas que ofertan enoturismo en los valles vitivinícolas de Baja California, conformada por promotores, restauradores, hoteleros o propietarios de alojamientos turísticos, y bodegas; y, como valor agregado (iv) un estudio georreferenciado de la ubicación exacta de la oferta, a sabiendas que la georreferenciación o rectificación consiste en un proceso que permite determinar la posición de un elemento a través de un sistema de coordenadas en un lugar geográfico espacial; este sistema se usa frecuentemente en los sistemas de información geográfica (Dávila y Camacho, 2012). Por esta razón, se espera obtener información referente a: (i) perfil del empresario; (ii) información de la empresa; (iii) actividades productivas; (iv) recursos y capital humano; (v) infraestructura, vías de acceso, seguridad y señalización; (vi) estrategias de promoción y comercialización; (vii) uso de las tecnologías de la información y la comunicación; (viii) actividades turísticas; y, (ix) aspectos de la demanda. 
Figura 10. Ruta del Queso y el Vino del Querétaro

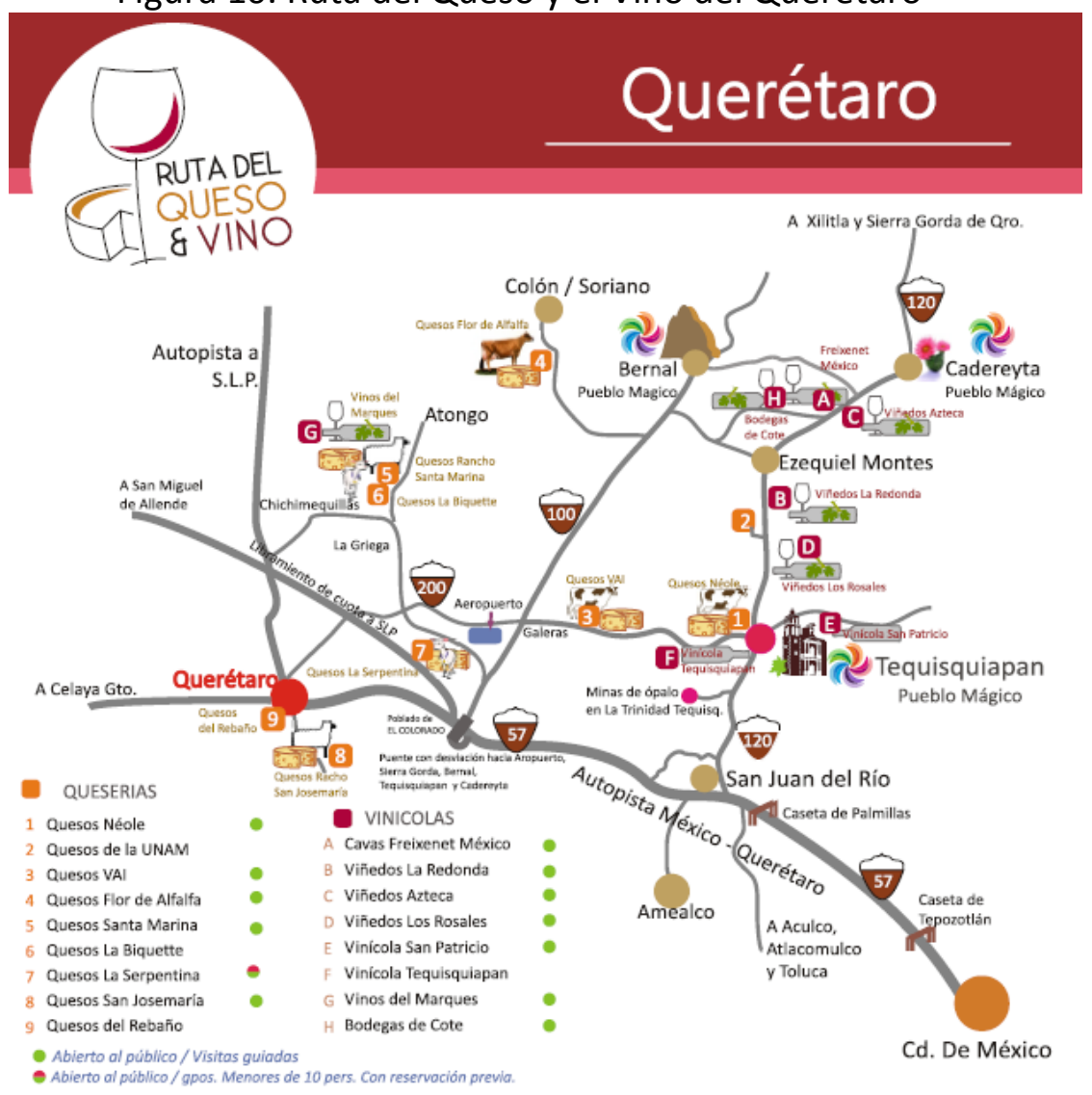

Fuente: Consejo de la Ruta del Queso y el Vino A. C. (2015).

Para concluir este artículo se deja en evidencia que la capacitación posterior a la obtención de resultados de esta propuesta será también de beneficio para la zona vitivinícola de Querétaro, y como consecuencia, aplicar la misma metodología para llevar adelante un nuevo estudio en esta región, obtener resultados y establecer comparaciones entre ambos territorios. Lo que a su vez nutrirá el conocimiento y generará nuevos aportes estadísticos del turismo en el país. Concibiéndose de forma ampliada en un estudio de diseño y aplicación de un sistema de información turística estadística para la planeación, gestión y marketing de las zonas vitivinícolas de México. 


\section{AGRADECIMIENTOS}

Los autores de este estudio agradecen al Consejo Nacional de Ciencia y Tecnología (CONACYT) por los fondos para la subvención del primer período de la Estancia Posdoctoral al Extranjero bajo la propuesta 239020. También se reconoce el apoyo de la Universidad de La Rioja por brindar la infraestructura y uso de espacios, así como a los bodegueros y vitivinicultores de las empresas vinícolas de Baja California y La Rioja Alta.

\section{REFERENCIAS BIBLIOGRÁFICAS}

Alpizar, V.A., y Maldonado, M.M. (2009). Integración de la Ruta del Vino en Querétaro, un producto innovador. Quivera Revista de estudios urbanos, regionales, territoriales, ambientales y sociales, 11(2), 97-109.

Amador, O. (2015, 6 de Mayo). México escala en competitividad turística: WEF. Periódico El Economista. Recuperado de http://eleconomista.com.mx/industrias/2015/05/06/mexico-escala-competitividadturistica-wef-0

Baja Traveler Guide (2014). Wine Country Valle de Guadalupe. The Official Concierge Guide, Collector's Edition, Summer-fall.

Banco Mundial (2012). Informe Anual 2012. Washington, DC: Banco Mundial.

Barco E. (2008). Análisis de un sector: el Rioja entre dos siglos. Gobierno de La Rioja, Logroño (España). Consejo de Agricultura, Ganadería y Desarrollo Rural.

Barco, E. (2014). Factores determinantes del funcionamiento económico del sector vitivinícola en la Denominación de Origen Calificada Rioja (DOCa Rioja) y su adaptación a los cambios en el entorno económico (Tesis de Doctorado). Logroño: Universidad de La Rioja.

Beverland, M. (2000). Wine tourism: a tale of two Conferences. International Journal of Wine Marketing, 12(2), 63-74.

Bringas, N.L., e Israel J.I. (2004). El turismo alternativo: una opción para el desarrollo local en dos comunidades indígenas de Baja California. Economía, Sociedad y Territorio, IV(015), 551-590.

Boletín Turismo (2013). Comunicado de Prensa No. 184 de la Confederación de Cámaras Nacionales de Comercio, Servicios y Turismo. México, D. F.

Cabello, S.A., y Pascual, N. (2015). La construcción del turismo en nuevos destinos: Luces y sombras. El caso de La Rioja (España). Revista de Ciencias Sociales y Humanidades, 24, 30-48.

Campo, S., Rubio, N., y Yagüe, M.J. (2008). Beneficios y costes del uso de las TIC para las empresas minoristas de distribución de electrodomésticos. Revista Distribución y Consumo, 11, 94-101.

Cavazos, M.T. (2012). Reporte Final del Proyecto: Situación actual y bajo escenarios de cambio climático de la industria vitivinícola de Baja California, México. Centro de Investigación Científica y de Educación Superior de Ensenada.

Celaya, D. (2014). El desarrollo del sector vitivinícola en Baja California (2000-2013): Un análisis desde la perspectiva del desarrollo endógeno (Tesis Doctoral). El Colegio de la Frontera Norte. 
Centro de Documentación Turística (2015). Boletín 95 de información Turística: Turismo, oportunidad para la competitividad de México. D.F.: Secretaría de Turismo del Gobierno Federal.

Charters, S., y Ali-Knight, J. (2002). Who is the wine tourist? Tourism Management, 23, 311319.

Colmenero, M. (2007). ¿Quién le pone cascabel al gato? Ponencia Primer Congreso Internacional de Turismo Enológico, Jerez de la Frontera, España.

Consejo de la Ruta del Queso y el Vino A. C. (2015). Mapa Ruta del Queso y Vino 2015. Recuperado de http://www.larutadelquesoyvino.com.mx/mapa-de-la-ruta-del-queso-yvino/

Consejo Regulador de la Denominación de Origen Calificada Rioja (2013). Memoria 2013. Logroño.

Dávila, F.J., y Camacho, E. (2012). Georreferenciación de documentos cartográficos para la gestión de Archivos y Cartotecas. Revista Catalana de Geografía, XVII(46).

Espejel, M.I., Ferrer, A., Leyva, J.C., y Santos, M. (2014). Turismo en el valle de Guadalupe: ¡Tanto qué hacer! En J.C. Leyva, \& M.I. Espejel (Coords.), El Valle de Guadalupe (pp. 94101). Universidad Autónoma de Baja California.

Freitas, S. (2015). Prácticas productivas empresariales, convenciones y desarrollo territorial rural: el caso de la Denominación de Origen vitivinícola española Méntrida. Cuadernos Geográficos, 54(2), 98-123.

González, S., y Fuentes, N.A. (2013). Matriz de insumo-producto vitivinícola de Baja California, México. Revista de Economía, XXX(81), 57-88.

Grupo Fórmula (2015, 17 de Mayo). Anuncia Sectur líneas de acción en apoyo a productores de vino. Recuperado de http://www.radioformula.com.mx/notas.asp?Idn=502650\&idFC=2015

Hall, C.M., y Mitchell, R. (2000). Wine Tourism in Mediterranean: A Tool for Restructuring and Development. Thunderbird International Business Review, 42(4), 445-465.

Hernández, R., Fernández, C., y Baptista, P. (Eds.) (2010). Metodología de la investigación. México: MC Graw-Hill Interamericana.

Instituto de Estadística de La Rioja (2014). Principales características demográficas de La Rioja. Logroño: Gobierno de La Rioja.

Instituto de Turismo de España (2014). Plan Integral de Turismo Rural. Madrid.

Instituto Español de Comercio Exterior (2012). El mercado de vino en México. Madrid: Oficina Económica y Comercial de la Embajada de España en México.

Lampón, J.F., y Martínez, A.I. (2005). Marketing en Internet: el sector vitivinícola gallego. Revista de Estudios Regionales, (73), 107-129.

Liberman, S., Baena, V., y Moreno, F. (2009). La expansión internacional de la industria vitivinícola chilena. Estudio empírico de los factores y nivel exportador. Cuadernos de Gestión, 10(1), 35-73.

López, V., y Sotelo, C. (2014). Los vinos del Valle de Guadalupe: Análisis de su comercialización. European Scientific Journal, 10(4), 90-106.

Mac Kay, C. (2014). Hilando fino con el agua y el vino. En J.C. Leyva, \& M.I. Espejel (Coords.), El Valle de Guadalupe (pp. 37-48). Universidad Autónoma de Baja California.

Maldonado, G., Martínez, M., García, D., Aguilera, L., y González, M. (2010). La influencia de las TICs en el rendimiento de la PyME de Aguascalientes. Revista Investigación y Ciencia, (47), 57-65. 
Mexican Business Web (2015, 16 de Abril). México regresa al Top Ten del ranking mundial de Turismo. Recuperado de http://www.mexicanbusinessweb.mx/sector-de-servicios-enmexico/mexico-regresa-al-top-ten-del-ranking-mundial-de-turismo/

Meraz, L. (2015). Estrategias de competitividad de las micro, pequeñas y medianas empresas vinícolas de la Ruta del Vino del Valle de Guadalupe. Mexicali: Departamento de Editorial Universitaria de la Universidad Autónoma de Baja California.

Mitchell, R., y Hall, C.M. (2006). Wine tourism research: the state of play. Tourism Review International, 9(4), 307-332.

Moreno, J.J. (2011). Impacto de la carga fiscal en la competitividad de pequeñas empresas, en Ensenada, Baja California: Análisis del ejercicio 2011. En N. Herrera (Ed.), Redes de Innovación, Energías Renovables y Competitividad (pp. 11-131). Ensenada: Editorial Fundación Teleddes.

Organización Mundial del Turismo (2015, 27 de Enero). Comunicado de Prensa No. 15006: Más de 1.100 millones de turistas viajaron al extranjero en 2014. Recuperado de http://media.unwto.org/es/press-release/2015-01-27/mas-de-1100-millones-deturistas-viajaron-al-extranjero-en-2014

Palmas, Y.D., Serrano-Barquín, R.C., Gutiérrez, J.G., Cruz, G., y Favila, H. (2014). Modelo Teórico-Metodológico para el estudio del turismo armónico y el desarrollo local. Investigaciones Turísticas, (7), 23-46.

Paredes, M. (2015, 8 de Mayo). México sube 14 sitios en el índice turístico. Periódico Excelsior. Recuperado de http://www.excelsior.com.mx/nacional/2015/05/08/1023043

Pérez, J.C., Muñoz, G.A., y López-Guzmán, T. (2015a). Motivación y satisfacción turística en los festivales del vino: XXXI ed. cata del vino Montilla-Moriles, España. Tourism \& Management Studies, 11(2), 7-13.

Pérez, J.C., Muñoz, G.A., y López-Guzmán, T. (2015b). Wine Festivals as a Vehicle of Promotion of a Tourist Destination. Mediterranean Journal of Social Sciences, 6(352), 574-581.

Prat, J.M., y Cànoves, G. (2014). Las rutas del vino del Empordà y del Priorat y su dinámica relacional. Dos destinos con diferente grado de desarrollo del turismo enológico y una dinámica relacional similar. Estudios Geográficos, LXXV(277), 683-705.

Quiñónez, J.J., Bringas, N.L., y Barrios, C. (2012). La Ruta del Vino de Baja California. Patrimonio Cultural y Turismo Cuadernos, (18), 131-150.

Ruiz, A.V., y Pelegrín, J. (2011). Estrategias empresariales seguidas enoturismo enológico: Análisis de casos prácticos españoles. En C. Flavián, \& C. Fandos (Eds.), Turismo gastronómico: estrategias de marketing y experiencias de éxito (pp. 119-190). Universidad de Zaragoza.

Ruiz, A.V., Campo, A., y Riaño, C. (2013). Reporte de investigación de la Satisfacción del consumidor: Antecedentes y consecuencias sobre las decisiones de compra de los vinos con DOCa Rioja. Universidad de La Rioja.

Ruiz, J.G., Martínez, O.C., Verján, R., y Valderrama, J.A. (2011). Aproximaciones al turismo enológico y sus estrategias de mercadotecnia en México. Gestión Turística, (16), 137155.

Ruiz, A.V., y Riaño, C. (2011). Las marcas privadas en el sector vitivinícola español, Logroño, Departamento de Economía y Empresa, Documento de Trabajo.

Ruiz, W. (2014). Elementos para un diagnóstico de la vitivinicultura en México. Revista de Economía, XXXI(83), 9-50. 
Secretaría de Turismo (2015). Boletín 161: Sector Turismo, el mayor generador de empleos: Enrique de la Madrid. D.F.: Secretaría de Turismo del Gobierno Federal.

Secretaría de Turismo (2014). Boletín 30: El turismo, fundamental para la imagen de México a nivel nacional y ante el mundo: Ruiz Massieu. D.F.: Secretaría de Turismo del Gobierno Federal.

Secretaría de Turismo del Estado de Baja California (2014a). Boletín de Las fiestas de la vendimia y el turismo enológico en Baja California. Tijuana: Observatorio Turístico de Baja California.

Secretaría de Turismo del Estado de Baja California (2014b). Folleto digital de la Ruta del Vino. Recuperado de http://descubrebajacalifornia.com/images/folletosinstitucionales pdf/Folleto-Ruta-del-Vino.pdf

Secretaría de Turismo del Estado de Baja California (2011). Folleto de la Ruta del Vino del Baja California. Tijuana, Baja California.

Secretaría de Turismo del Estado de Querétaro (2013). Rutas de Querétaro. Santiago de Querétaro, Querétaro. Recuperado de http://www.queretaromaraton.com/uploads/archivos/3 $27 \quad 295956210$ rutas quereta ro.pdf

Segundo Informe de Ejecución (2014). Plan Nacional de Desarrollo 2013 - 2018. México: Gobierno Federal.

Trejo-Pech, C.O., Arellano-Sada, R., Coelho, A.M., y Weldon, R.N. (2012). Is the Baja California, Mexico, Wine Industry a Cluster? 2011 AAEA anual meeting in Pitsburgh, PA.

Trejo-Pech, C.O., López-Reyna, C., House, L.A., y Sarmiento-Pérez, F.J. (2010). Globalization in the Wine Industry and the Case of Baja California Mexico. 20 ${ }^{\text {th }}$ Annual World Food and Agribusiness Forum and Symposium 2010, Boston, USA.

Treviño, E., Heald, J., y Guerrero, R. (2015). Un modelo del gasto con factores sociodemográficos y de hábitos de viaje en Pueblos Mágicos del Estado de Guanajuato, México. Investigaciones Turísticas, (10), 117-149.

Valderrama, J.A., y Meraz, L. (2012). Turismo, actividad económica y cambio climático en México. Escenario relacionado y compartido hacia el desarrollo sustentable. En T. Cuevas, y A. Palafox (Coords.), Turismo en la frontera del conocimiento: entre la modernidad y la posmodernidad (pp. 125-140). Universidad Autónoma de Ciudad Juárez.

Velarde, E., Araiza, Z., Hernández, N., y Tobías, L. (2011). Estrategias de dirección y tecnologías de información en pequeñas y medianas empresas de Coahuila. Revista Internacional Administración \& Finanzas, 4(1), 19-30.

Velásquez, G.A. (2007). Diseño de un modelo de sistema enoturístico para la región vitivinícola del estado de Querétaro (Tesis de Maestría). D.F.: Instituto Politécnico Nacional.

Vieira, A., López-Guzmán, T., y Rodríguez, J. (2013). Análisis del enoturista en la Denominación de Origen del Jerez-Xérès-Sherry (España). Tourism \& Management, 9(2), 37-43.

Para citar este artículo: Meraz, L.; Ruiz, A.V. (2016). El enoturismo de Baja California, México: Un análisis de su oferta y comparación con la región vitivinícola de La Rioja, España. Investigaciones Turísticas, (12),73-98. http://dx.doi.org/10.14198/INTURI2016.12.04 